\title{
Diagnóstico para o gerenciamento dos resíduos sólidos em oficina mecânica: estudo de caso em concessionária do município de Frederico Westphalen - RS
}

Diagnosis for the management of solid waste in the machine shop: a case study in the municipality of dealership in Frederico Westphalen - RS.

\author{
Ademir Eloi Gerhardt, Fernanda Caroline Drumm, Patricia Grassi, Bruno Acosta Flores, Aline Custódio \\ Ferrão Passini, Willian Fernando de Borba, Pedro Daniel da Cunha Kemerich \\ Laboratório de Planejamento e Monitoramento Ambiental - LPMA/UFSM, \\ Curso de Engenharia Ambiental da Universidade Federal de Santa Maria - UFSM/CESNORS
}

\section{Resumo}

\begin{abstract}
O setor mecânico tem crescido continuamente associado ao crescimento na produção e venda de veículos novos no país, ocorrendo assim, um grande aumento da frota de veículos. Com a maior circulação destes, cresce também a necessidade de ter oficinas mecânicas para atender essa a demanda, oficinas estas, que realizam diversos serviços como a troca de peças e lubrificantes, ajustes no motor e serviços de manutenção elétrica. Destes serviços, das oficinas mecânicas, resultam resíduos como os óleos usados, as peças metálicas, as estopas e embalagens contaminadas com óleo, entre outros. Tendo em vista o potencial poluidor dessa atividade, que gera consideráveis quantidades de resíduos perigosos, bem como a necessidade da correta gestão destes resíduos, o presente trabalho faz uma análise da gestão dos resíduos da oficina de uma concessionária, localizada no norte do estado do RS, através de um o diagnóstico da gestão dos resíduos sólidos, a fim de propor um melhor gerenciamento para adequação do setor.
\end{abstract}

Palavras-chave: Gerenciamento, Resíduos Sólidos, Oficina Mecânica.

\begin{abstract}
The mechanical sector has grown steadily due to the growth in production and sales of new vehicles in the country, occurring with this, a large increase in the vehicle fleet in the country. With the largest such vehicles, so too does the need for mechanical workshops to meet this fleet, these workshops that perform various services such as the exchange of parts and lubricants, adjustments to the engine and electrical maintenance services. These services from repair shops, resulting wastes such as waste oils, metal parts, the tow and packing materials contaminated with oil, among others. Given the pollution potential of this activity generates considerable quantities of hazardous waste as well as the need for proper management of these wastes, this paper analyzes the waste management workshop from a dealership, located in the northern state of RS, through a diagnosis of solid waste management in order to offer a better management for fitness industry.
\end{abstract}

Keywords: Management, Solid Waste, Mechanical Workshop. 


\section{INTRODUÇ̃̃O}

Segundo as normas da ISO 14000 (2004), a gestão ambiental consiste em um conjunto de medidas e procedimentos bem definidos que, se adequadamente aplicados, permitem reduzir e controlar os impactos introduzidos por um empreendimento sobre o meio ambiente.

As atividades desenvolvidas por oficinas mecânicas, relacionadas à reparação de veículos automotores, geram diferentes tipos de resíduos sólidos e efluentes que precisam de tratamento adequado para que seu descarte não cause danos ao meio ambiente e a saúde pública. As principais atividades como: troca de óleo lubrificante, fluidos de arrefecimento e hidráulicos, troca e limpeza de peças, retífica de motores, injeção eletrônica, suspensão, freios, regulagem de motor, alinhamento e balanceamento, entre outras desenvolvidas por oficinas mecânicas, geram grande quantidade de resíduos sólidos, entre os principais encontram-se peças usadas, pneus, latarias, flanela, estopas sujas, papelão e embalagens de peças e de óleos lubrificantes (NUNES; BARBOSA, 2012).

Apesar das questões ambientais que envolvem esse tipo de atividade, por possuírem resíduos que podem ser considerados perigosos esses empreendimentos não são objetos de licenciamento ambiental e ainda não se tem normas específicas às quais possam regularizar essas atividades. $\mathrm{E}$ necessário cada vez mais definir práticas que reduzam a geração dos resíduos sólidos, a separação desses na fonte geradora no caso a própria oficina, o destino adequado dos resíduos como também a redução da geração de efluentes e seu tratamento antes de ser lançado na rede de esgoto (PAULINO, 2009).

Os resíduos sólidos são classificados, segundo a NBR-10.004 da ABNT (Associação Brasileira de Normas Técnicas), de acordo com características de periculosidade apresentada, sendo Classe I (perigosos) ou Classe II (não-perigosos) sendo classe II A - Inertes e Classe II B - Não inertes. Dessa forma, o tratamento, armazenamento, transporte e destinação final dos mesmos devem seguir diretrizes normativas para controle e prevenção de possíveis impactos ambientais.

Resíduos sólidos segundo a classificação da NBR 10.004 são determinados resíduos nos estados sólidos e semissólidos, resultantes das atividades industriais, domésticas, hospitalares, comerciais, agrícolas, de serviços e de varrição, e também os lodos provenientes de sistemas de tratamento de água, aqueles gerados em equipamentos e instalações de controle de poluição, bem como determinados líquidos cujas particularidades tornem inviável o seu lançamento na rede pública de esgotos ou corpos de água, ou exijam para isso soluções técnicas e economicamente inviáveis em face a melhor tecnologia disponível (ABNT 14004).

De acordo com a NBR 10.004, os resíduos são divididos em duas classes, sendo, resíduos Classe I- Perigosos e resíduos Classe II Não Perigosos (II A- Não Inertes e II B- Inertes). Os resíduos classe I - Perigosos, são todos os resíduos que possuem propriedades físicas, químicas ou infectocontagiosas as quais podem causar riscos à saúde pública e/ou riscos ou danos ao meio ambiente, quando gerenciado de forma inadequada. Para que um resíduo seja apontado e considerado perigoso, ele deve estar contido nos anexos A ou B da NBR 10004 ou apresentar uma ou mais das seguintes características, (inflamabilidade, corrosividade, reatividade, toxicidade e patogenicidade).

Os resíduos classe II - Não Perigosos são divididos em inertes e não inertes, sendo considerados resíduos classe II-A (Não Inertes), os resíduos que apresentam propriedades como biodegradabilidade, combustibilidade ou solubilidade em água e não se enquadram na classificação acima, Classe - I Perigosos e nem na classe II B- Inertes. Já os resíduos classe IIB (Inertes), são todos os resíduos que quando amostrados de uma forma representativa, segundo a ABNT NBR 10007, e submetidos a um contato dinâmico e estático com água destilada ou deionizada, à temperatura ambiente, conforme ABNT NBR 10006, não tiverem nenhum de seus constituintes solubilizados a concentrações superiores aos padrões de potabilidade de água, excetuando-se aspecto, cor, turbidez, dureza e sabor.

Segundo Saviczki (2012), para que ocorra um gerenciamento adequado dos resíduos sólidos é fundamental a correta segregação, acondicionamento, armazenamento temporário, transporte externo, tratamento ou destino final dos resíduos gerados por cada empreendimento.

De acordo com a ABRAMAC (Associação de Proteção ao Meio Ambiente de Cianorte) a separação na fonte é uma estratégia fundamental para garantir a reciclagem de resíduos. A contaminação de qualquer resíduo com óleo lubrificante automotivo usado pode inviabilizar técnica ou financeiramente o gerenciamento. A segregação contribui para um menor volume de resíduos perigosos a ser tratado ou disposto em Aterros de Resíduos Perigosos. Após a separação na fonte, os 
Quadro 1. Código das cores para segregação dos resíduos.

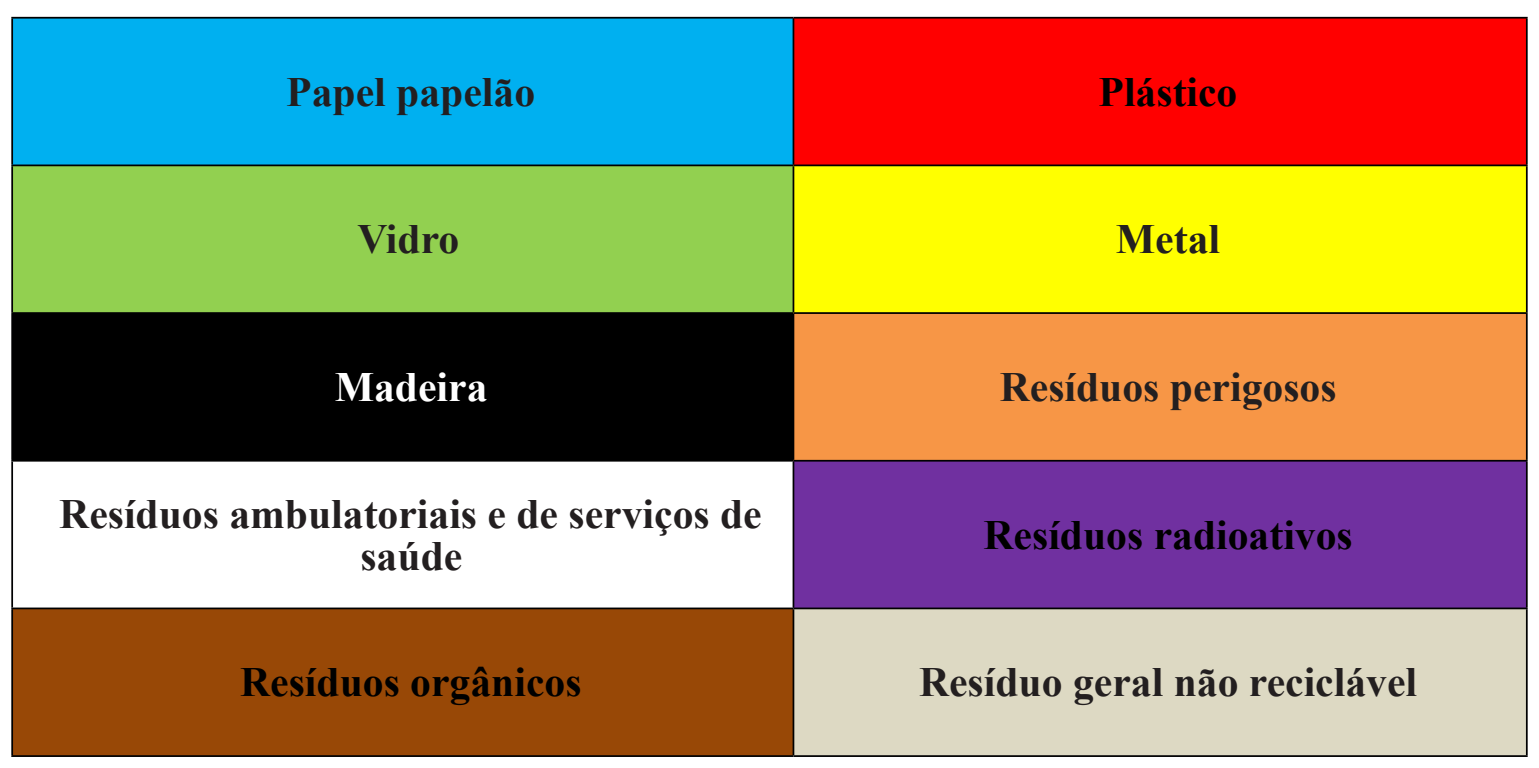

resíduos devem ser adequadamente armazenados, aguardando o encaminhamento ao tratamento ou a disposição final.

Todos os resíduos provenientes das atividades da oficina mecânica, escritório, e refeitório deverão ser segregados de acordo com a resolução 275/01 do CONAMA (Conselho Nacional do Meio Ambiente), a qual estabelece o código de cores para os diferentes tipos de resíduos, e a identificação dos coletores e transportadores. A resolução CONAMA 275 expõe o código de cores para os diferentes tipos de resíduos, como uma forma de facilitar a visualização da segregação dos resíduos na fonte, podendo assim reduzir ao máximo a disposição em aterros de matérias que podem ser reciclados. No Quadro 1 é possível observar o código de cores para separação correta dos resíduos.

$\mathrm{O}$ acondicionamento dos resíduos e outro item importante, este consiste no ato de embalar os resíduos segregados, em sacos ou recipientes como tambores e contêineres que evitem vazamentos e resistam às ações de ruptura. A capacidade dos recipientes de acondicionamento deve ser compatível com a geração diária de cada tipo de resíduo. $\mathrm{O}$ acondicionamento dos resíduos de oficina mecânica pode ser realizado em contêineres, tambores, tanques ou a granel.

Segundo a NBR 12235/92 resíduos ou substâncias que, ao se misturarem, provoquem efeitos indesejáveis, como fogo, liberação de gases tóxicos ou ainda que facilitem a lixiviação de substâncias tóxicas, não devem ser colocados em contato. Em anexo nesta mesma norma é possível ver alguns prováveis efeitos indesejáveis resultantes da mistura de alguns resíduos perigosos.

Todos os resíduos devem ser armazenados de maneira a não possibilitar a alteração de sua classificação e deforma que sejam minimizados os riscos de danos ambientais. Os resíduos da classe II não devem ser armazenados juntamente com resíduos classe I, em face da possibilidade da mistura resultante ser caracterizada como resíduo perigos(NBR 11174/90). Caso haja mistura de resíduos de classes diferentes, um resíduo não perigoso pode ser contaminado e tornar-se perigoso, dificultando seu gerenciamento e aumentando os custos a ele associados.

As áreas destinadas à armazenagem dos resíduos devem ser cobertas, a fim de evitar a ação da chuva e de outras intempéries, garantindo condições de segurança, até que este seja transportado para a disposição final.

O transporte externo de alguns resíduos de oficinas mecânicas para a sua disposição final, como o óleo lubrificante usado, deve ser realizado por empresa licenciada para este fim, pois esta atividade apresenta potencial de risco. Segundo a resolução CONAMA 362/2005, as empresas que fazem esse transporte devem estar cadastradas no Órgão Regulador da Indústria de Petróleo (ANP) e licenciadas pelo órgão ambiental competente. Veículos coletores devem atender às normas da sinalização de segurança previstas no decreto 96.044 de 18 de maio de 1988 da Agência Nacional de Transportes Terrestres (ANTT). 
A última etapa para o correto gerenciamento de resíduos nas oficinas é a destinação final destes, sendo de grande importância na logística de manejo dos resíduos, uma vez que depois do gerenciamento adequado desses materiais no empreendimento, o mesmo deve ser depositado em locais que garantam a preservação do meio ambiente, ou ainda podem, dependendo do material receber algum tratamento, como a reciclagem, incineração ou compostagem. O tratamento dos resíduos procede visando a sua reutilização ou pelo menos sua inertização, de forma não prejudicar o meio ambiente e a saúde da população (LACOURT, 2012).

De acordo com Valle (2002) a caracterização dos resíduos gerados ou acumulados em um estabelecimento tem papel importante na escolha da melhor solução para seu tratamento ou disposição. Dada à diversidade destes resíduos, não existe um processo de tratamento preestabelecido, havendo sempre a necessidade de realizar pesquisas e desenvolvimento de processos economicamente viáveis e eficientes.

É notório que as atividades praticadas no setor mecânico contribuem assiduamente na geração de resíduos perigoso a qual merece atenção especial de acordo com Lopes \& Kemerich (2007) a falta de gerenciamento desses resíduos, por partes das oficinas mecânicas, pode gerar problemas ambientais devido à quantidade de compostos químicos presentes neste meio. Tendo isso em vista, este trabalho teve como objetivo identificar os resíduos gerados na oficina mecânica de uma concessionária do município de Frederico Westphalen-RS, analisando o gerenciamento destes na oficina e apontar possíveis ações que podem ser implantadas para a melhoria da gestão.

\section{MATERIAIS E MÉTODOS}

A metodologia utilizada neste trabalho foi baseada em visitas ao local de estudo e no acompanhamento da geração de resíduos, identificando as classes dos resíduos existentes assim como, os procedimentos de manejo dos resíduos como, armazenamento, segregação, coleta e destinação final, identificando os pontos críticos do empreendimento, e apontando as estratégias de minimização.

O estudo de caso foi realizado na oficina mecânica de uma concessionária do município de Frederico Westphalen, município situado na região norte do estado do RS (Figura 1).

Para melhor compreender funcionamento de uma oficina mecânica, foi elaborado um fluxograma (Figura 2) demonstrando as etapas e os principais resíduos gerados desde a chegada até a saída de um automóvel à oficina.

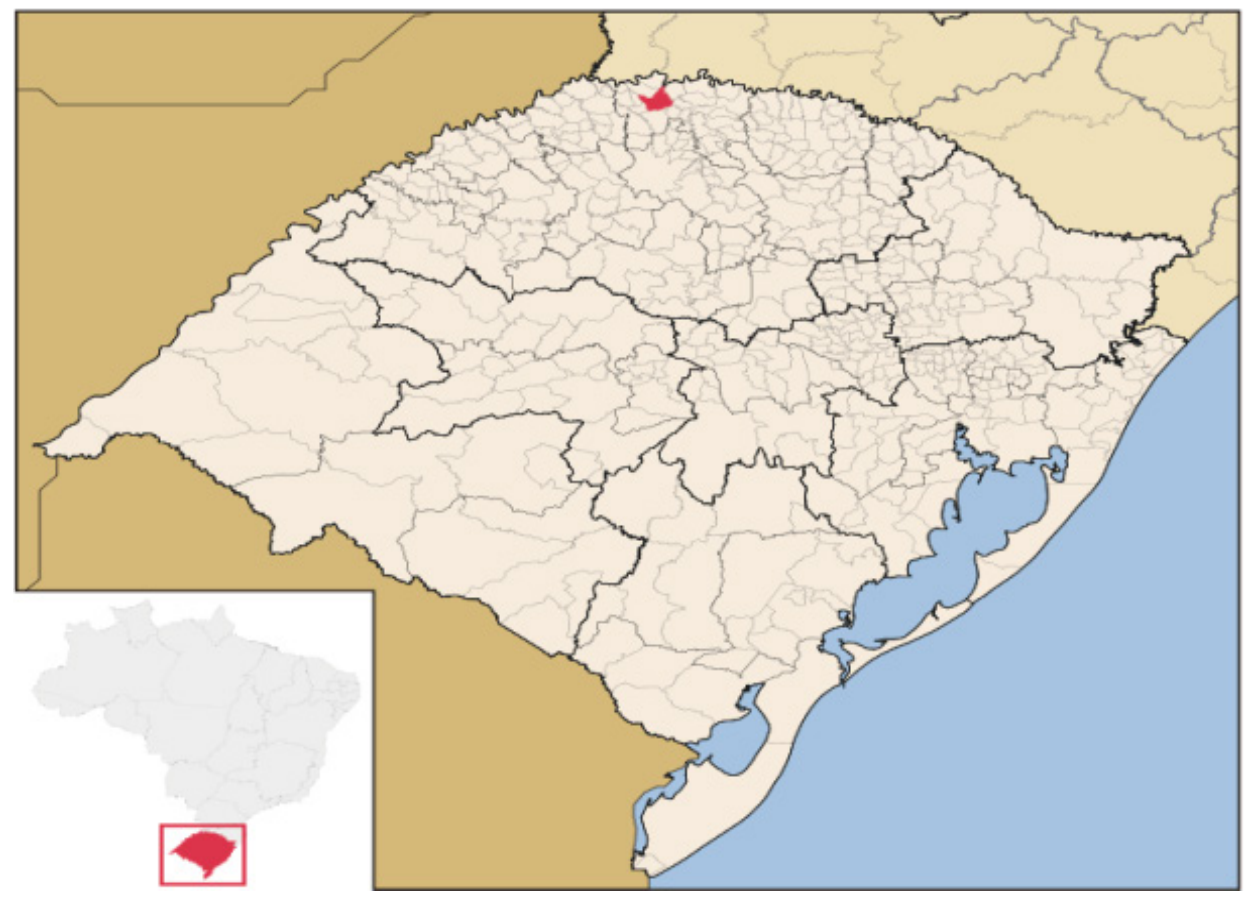

Figura 1. Localização do município de Frederico Westphalen- RS

Fonte: http://pt.wikipedia.org/wiki/Ficheiro:RioGrandedoSul_Municip_FredericoWestphalen.svg 


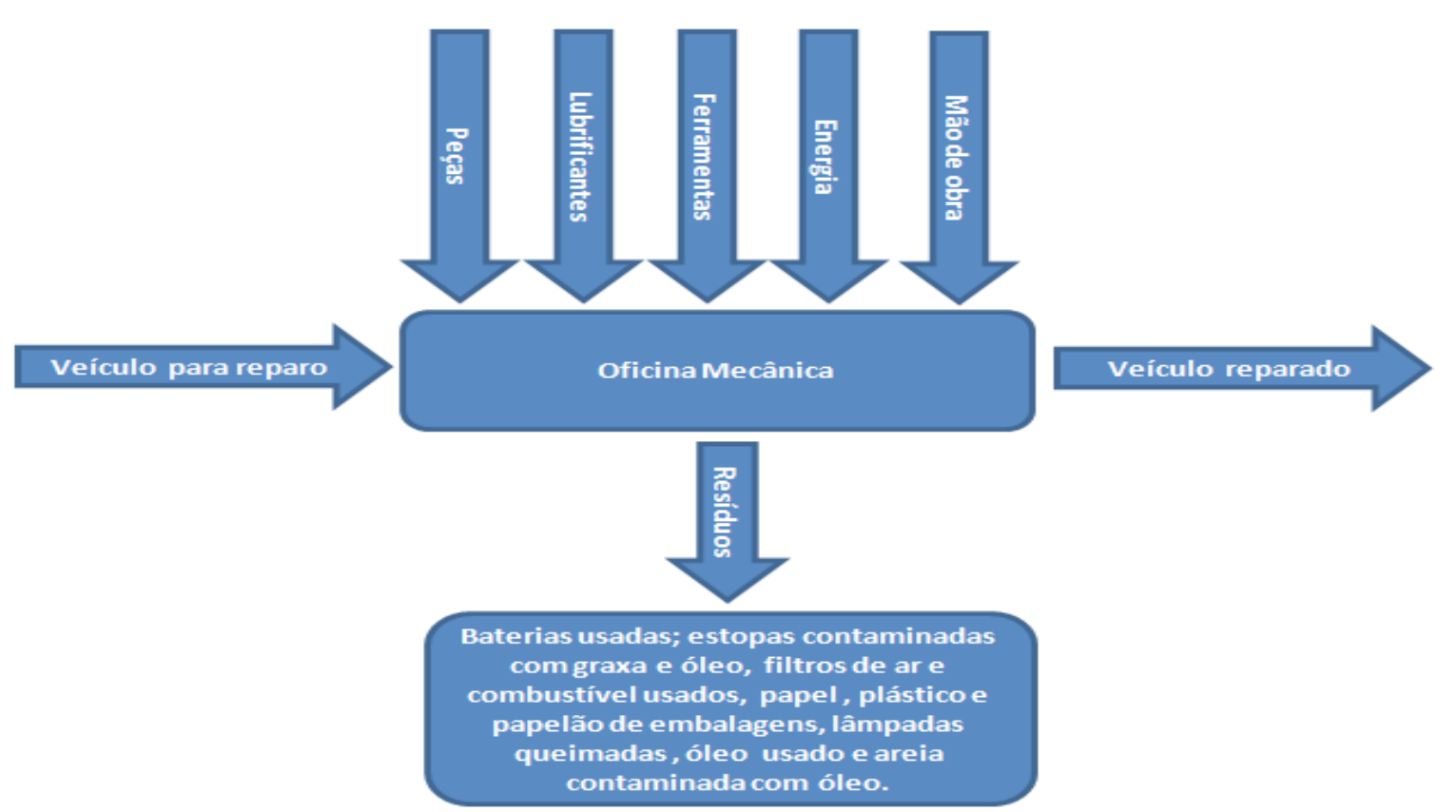

Figura 2. Fluxograma do processo de reparo de veículo automotor

\section{RESULTADOS E DISCUSSÃO}

Os resíduos identificados na empresa foram: papel e papelão, plásticos, peças metálicas, estopas contaminadas, óleo lubrificante, elementos filtrantes de óleo, de combustível (etanol, gasolina, diesel), frascos plásticos e metálicos de lubrificantes.

O Quadro 2 mostra os resíduos identificados, a classe correspondente, o acondicionamento temporário e final, o armazenamento e o destino final (empresa responsável) dos resíduos gerados na oficina.

Acondicionamento e destino dos resíduos na empresa de acordo com o tipo e a classe.

Os óleos lubrificantes devem ficar armazenados em recipientes com boas condições e colocados dentro de uma área de contenção, a qual é sempre essencial, evitando que o óleo lubrificante usado ou contaminado se espalhe em caso de rompimento ou acidente na colocação ou retirada do resíduo das bombonas, latões ou tanques.

Dentre os recipientes destacam-se as bom-

Quadro 2. Óleos lubrificantes

\begin{tabular}{|c|c|c|c|c|c|}
\hline Resíduo & Classe & $\begin{array}{c}\text { Acondicionamento- } \\
\text { temporário }\end{array}$ & Acondicionamento final & Armazenamento & Destino/empresa \\
\hline Óleo usado & I & Coletor & Tanque & Dentro da oficina & LWART lubrificantes \\
\hline $\begin{array}{c}\text { Embalagens } \\
\text { contaminadas } \\
\text { com óleo }\end{array}$ & I & Tonel & $\underset{\text { coleta }}{\text { Embalagem plástica de }}$ & Dentro da oficina & $\begin{array}{c}\text { MB engenharia e meio } \\
\text { ambiente }\end{array}$ \\
\hline$\underset{\text { trantes }}{\text { Elementos fil- }}$ & I e II & Tonel & $\begin{array}{c}\text { Embalagem plástica de } \\
\text { coleta }\end{array}$ & Dentro da oficina & $\begin{array}{l}\text { GEAB logística am- } \\
\text { biental }\end{array}$ \\
\hline $\begin{array}{c}\text { Papel, papelão e } \\
\text { plástico }\end{array}$ & II-A & Lixo comum & Lixo comum & Pátio & Coleta pública \\
\hline Peças metálicas & II-B & Tonel & Tonel & Dentro da oficina & $\begin{array}{l}\text { GEAB logística am- } \\
\text { biental }\end{array}$ \\
\hline Estopas & I & Tonel & $\begin{array}{l}\text { Embalagem plástica de } \\
\text { coleta }\end{array}$ & Dentro da oficina & $\begin{array}{l}\text { GEAB logística am- } \\
\text { biental }\end{array}$ \\
\hline
\end{tabular}




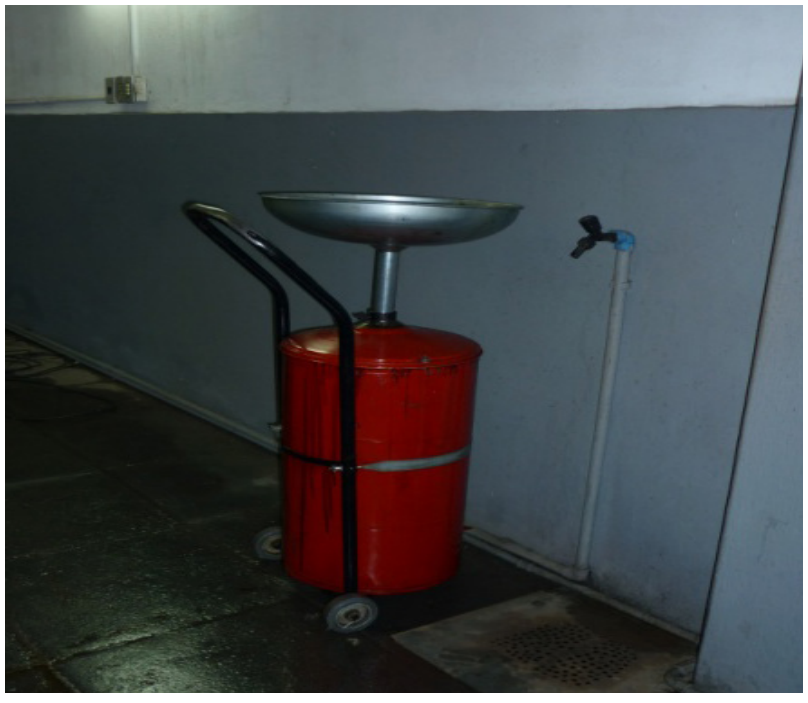

Figura 3. Coletor de óleo

bonas e "contêineres" plásticos, pela sua praticidade, resistência e durabilidade, e os tambores de latão, que merecem cuidado especial em relação à possível ataque por ferrugem ou amassados.

$\mathrm{Na}$ empresa, o óleo primeiramente é acondicionado em um coletor (Figura 3), quando este coletor fica cheio, o óleo contido nele é transferido para um tambor de PVC (Figura 4) ficando armazenado até que a empresa responsável (LWART lubrificantes) venha e efetue a coleta.

\section{I Embalagens contaminadas com óleo}

As embalagens usadas devem ser escorridas de forma a retirar todo o óleo, que geralmente fica nos frascos. A separação das embalagens deve ser feita de acordo com as características do resíduo, em embalagens plásticas disponibilizadas pela

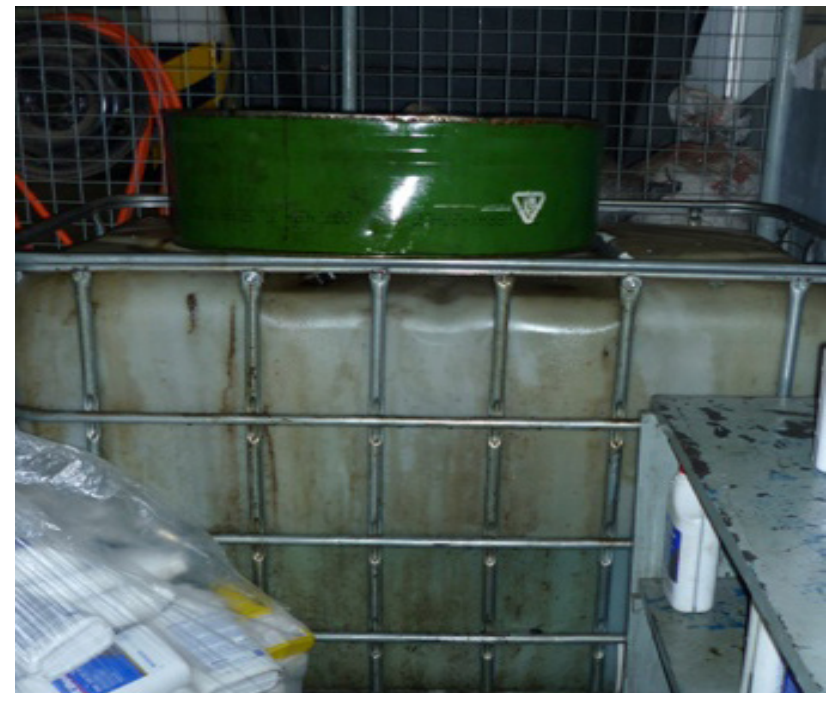

Figura 4. Tanque para armazenar óleo

empresa responsável pela coleta, as quais devem estar acondicionadas em áreas de contenção.

$\mathrm{Na}$ oficina estudada, as embalagens de óleos, depois de escorridas (Figura 5) são colocadas em sacos plásticos (Figura 6) e armazenadas em um canto da oficina. As tampas das embalagens de óleo são separadas, pois não chegam a ser contaminadas com o óleo devido ao lacre da embalagem. A empresa responsável pelo recolhimento das mesmas é a MB engenharia e meio ambiente, que recolhe as embalagens as quais no ato do recolhimento são pesadas, emitido laudo de recolhimento e transportadas até uma das unidades de armazenamento da MB. Neste local, as embalagens são conferidas e prensadas e após são transportadas para recicladores licenciados.

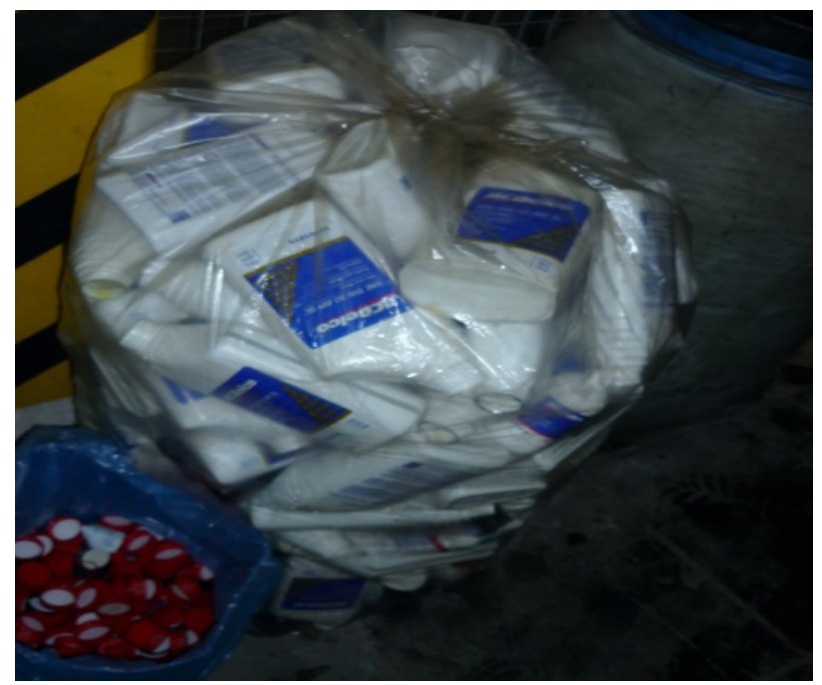

Figura 6. Acondicionamento em sacos

Figura 5. Embalagens sendo escorridas 


\subsection{Plásticos}

De acordo com a NBR 10004 que classifica os resíduos sólidos quanto a sua periculosidade, os plásticos determinados na empresa enquadram-se na classe II - B Inertes. Na empresa, os plásticos são acondicionados em lixeiras comuns e seu destino final é a coleta pública.

Grande parte da matéria prima utilizada na oficina mecânica vem embalada em plásticos. Ainda é produzido resíduos derivados do plástico no dia a dia, na utilização de copos descartáveis, utilizados para o consumo de café e de água. Esses resíduos são descartados no lixo comum, e levados pela coleta pública do município.

\subsection{Papel e papelão}

De acordo com a NBR 10004, que classifica os resíduos sólidos, o papel e o papelão se enquadram na classe II - A não inertes. O modo correto de estocar esses resíduos é em local coberto, a fim de que não entrem em contato com os demais resíduos para que não haja contaminação. Na empresa, não há estocagem de papel e papelão, apenas lixeiras simples (Figura 7), onde são depositados os mesmos, juntamente com plásticos.

Esses resíduos vão para o lixo comum, sendo levados pela coleta pública do município até o Consórcio Intermunicipal de Resíduos Sólidos (CIGRES).

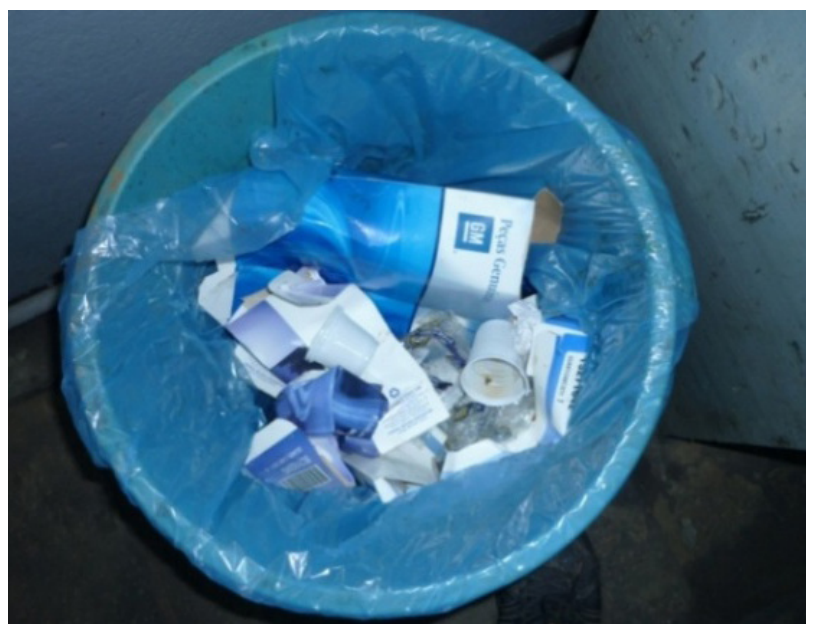

Figura 7. Lixeira.

\subsection{Estopas}

De acordo com a NBR 10004, as estopas se enquadram na classe I - Perigosos. A estocagem das estopas na empresa é realizada no interior da oficina.As estopas são utilizadas na limpeza das mãos, ferramentas e de peças e são acondicionadas em uma lixeira plástica (Figura 8). As estopas são recolhidas pela empresa GEAB logística ambiental que leva para seu destino final, sendo este a

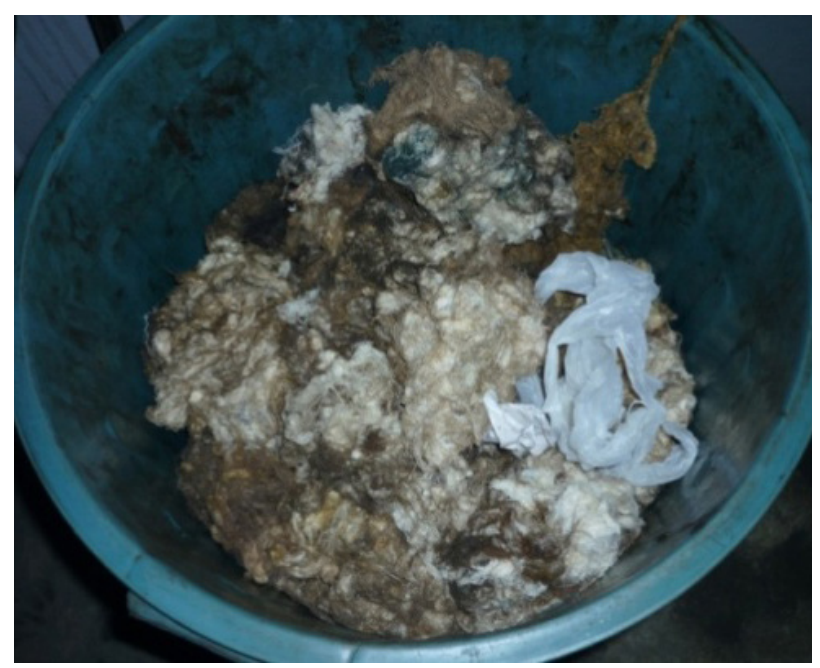

Figura 8. Estocagem das estopas incineração ou aterro sanitário.

\subsection{Metais}

Os metais descartados como resíduos na oficina (Figura 9) são provenientes da troca de peças de reparos em veículos. A NBR 10004 enquadra esses materiais na classe II - B Inertes. Sua estocagem é feita no interior da oficina, porém junto com os demais resíduos.

As peças metálicas são recolhidas pela empresa GEAB logística ambiental e enviadas à reciclagem, as quais separam o resíduo de acordo com sua composição,aço, alumínio, dentre outros, e posteriormente é encaminhado para empresas de fundição, onde servirá como matéria prima.

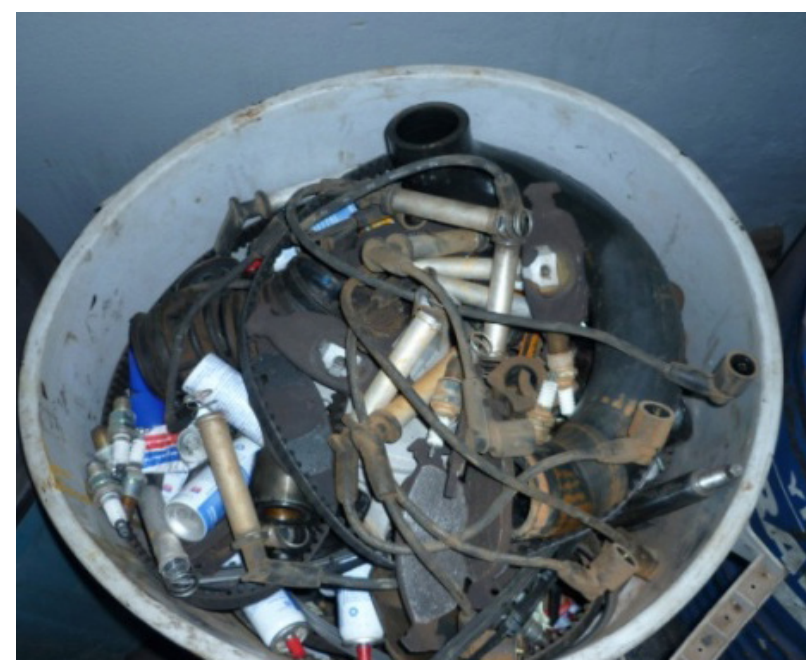

Figura 9. Estocagem de metais 


\subsection{Filtro de óleo}

Os filtros são levados para uma peça onde ficam dispostos a fim de escorrer o excesso de óleo, para depois serem acondicionados em tonéis de 200 litros.São recolhidos pela GEAB, empresa que presta consultoria ambiental para a empresa, e assim segue para sua destinação final.Os filtros devem ser coprocessados, o metal é enviado para a reciclagem e o elemento filtrante de papel destinado á incineração.

De acordo com a NBR 10004, os filtros de óleos se enquadram na classe I - Perigoso. A estocagem desse resíduo na empresa se dá em tonéis metálicos de 200 litros (Figura 10).

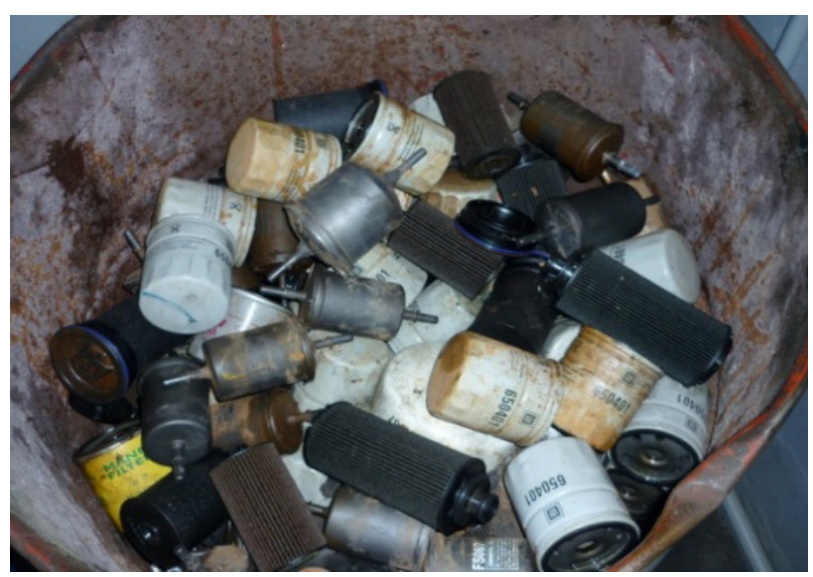

Figura 10. Filtros de óleo.

\subsection{Possíveis melhorias}

Referente ao acondicionamento dos resíduos, na empresa pode se perceber que pode ser melhorado (Figura 11). Por exemplo a padronização das lixeiras com suas cores indicativas para cada tipo de resíduo para melhor identificação (Figura 12).

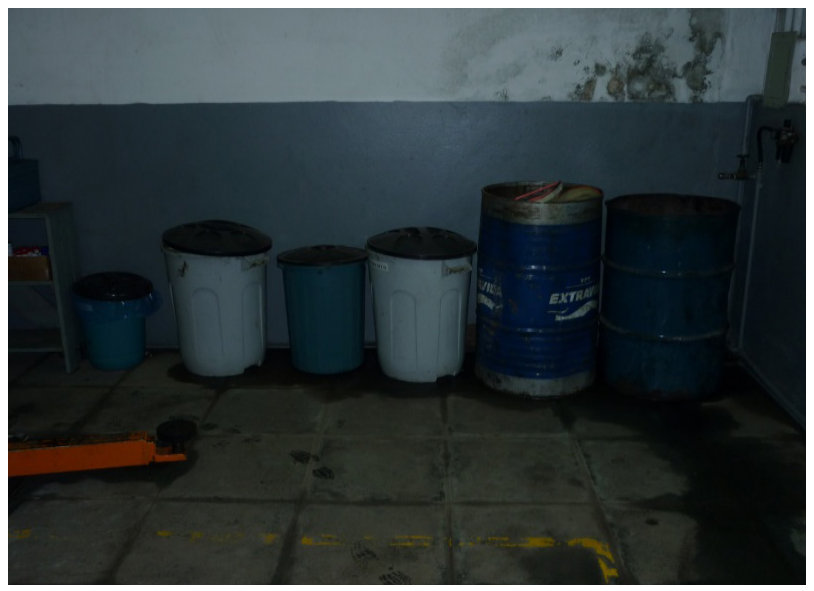

Figura 11. Lixeiras na oficina sem identificação Fonte. Sinal Verde Lixeiras

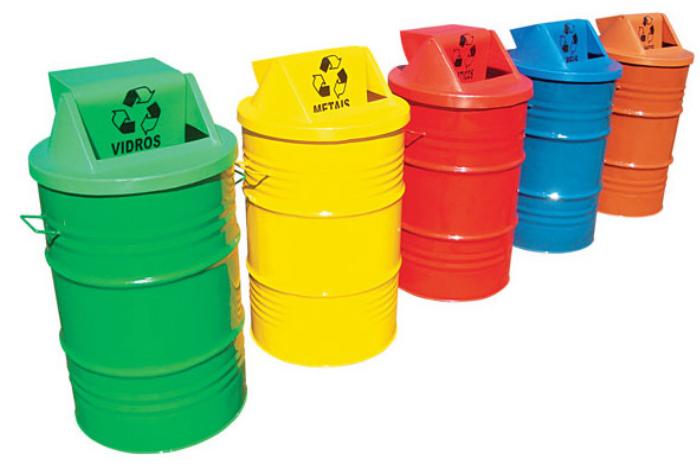

Figura 12. Tambores 200 L padronizadas.do tipo de resíduo. Fonte. Sinal Verde Lixeiras

Identificou-se a necessidade de ter ambiente apropriado para o armazenamento dos resíduos, pois os mesmos ficam dispostos pela oficina. Este espaço deveria apresentar uma área de contenção (Figura 13), com piso impermeável e divisões de acordo com o tipo de resíduo para o armazenamento correto deste. Pode ser observada a presença de manchas de óleo nas proximidades do reservatório de óleo lubrificante utilizado, que deve ter sido ocasionado devido a um possível vazamento ou derramamento (Figura 14).

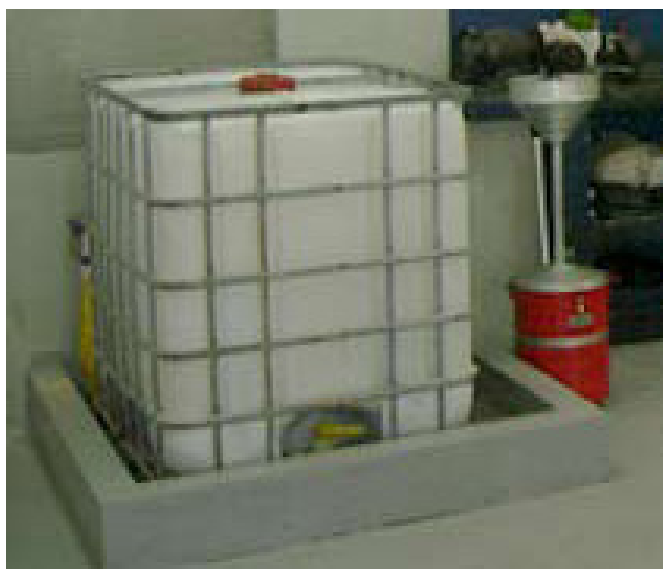

Figura 13. Container em bacia de

Fonte. ABRAMAC, 2008.

Constatou-se também a necessidade de uma caixa separadora de água e óleo, a qual é de suma importância e deve ser instalada pela concessionária pois os efluentes, quando lançados sem tratamento prévio nas redes coletoras de esgotos, podem poluir ou contaminar cursos d'água. Em municípios que não possuem Estação de Tratamento de Esgoto (ETE), os efluentes gerados pelas atividades das oficinas mecânicas são lançados in natura nos cursos d'água e, consequentemente, causam danos 


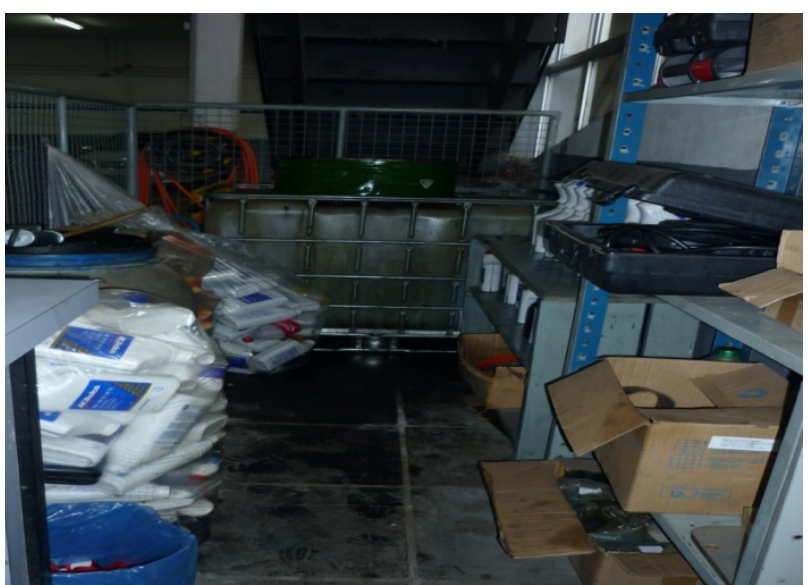

Figura 14. Manchas de óleo próximas ao reservatório de óleo lubrificante. contenção.

Fonte. ABRAMAC, 2008.

à saúde pública. Vários modelos de caixas separadora de água e óleo são disponíveis no mercado, podendo também ser construídas sob medida no próprio local, na figura abaixo é possível ver um modelo a venda no mercado (Figura 15).
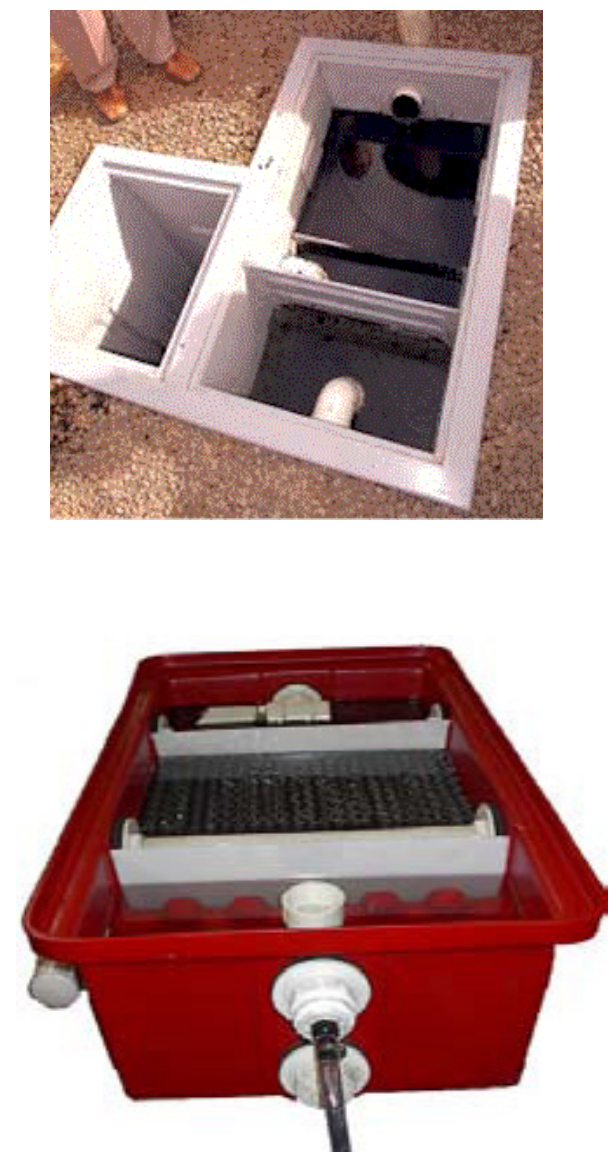

Figura 14. Exemplo de caixas separadora água e óleo comercial e sob medida.

Fonte: ABRAMAC, 2008.

\section{CONCLUSÃO}

A realização do gerenciamento dos resíduos sólidos adequado, auxilia na redução de impactos ao meio ambiente ocasionado pelas oficinas mecânicas. No estudo pode se observar que as maiores falhas estavam no acondicionamento e armazenamento dos resíduos na oficina, onde com algumas melhorias baseadas em ações e medidas simples e de baixo custo ter-se-ia uma grande melhora no gerenciamento dos resíduos. A correta gestão dos resíduos sólidos proporciona um desenvolvimento econômico aliado à preservação do meio ambiente.

\section{REFERÊNCIAS}

ASSOCIAÇÃO BRASILEIRA DE NORMAS TÉCNICAS - ABNT. NBR 12235: Armazenamento de resíduos sólidos Perigosos. Rio de Janeiro: ABNT, 1992.

ASSOCIAÇÃO BRASILEIRA DE NORMAS TÉCNICAS - ABNT. NBR 11174: Armazenamento de resíduos classes II - não inertes e III - inertes. Rio de Janeiro: ABNT, 1990.

ASSOCIAÇÃO BRASILEIRA DE NORMAS TÉCNICAS - ABNT. NBR ISO 10004. Resíduos Sólidos - Classificação. Rio de Janeiro: ABNT, 2004.

\section{ASSOCIAÇÃO BRASILEIRA DE NORMAS}

TÉCNICAS - ABNT. NBR ISO 14001. Sistemas da gestão ambiental - Requisitos com orientações para uso. Rio de Janeiro: ABNT, 2004.

\section{ASSOCIAÇÃO BRASILEIRA DE NORMAS}

TÉCNICAS - ABNT. NBR 10007: Amostragem de resíduos sólidos. Associação Brasileira de Normas Técnicas. Rio de Janeiro: ABNT, 2004.

ASSOCIAÇÃO BRASILEIRA DE NORMAS TÉCNICAS - ABNT. NBR 10006: Procedimento para obtenção de extrato solubilizado de resíduos sólidos. Rio de Janeiro: ABNT, 2004.

\section{ASSOCIAÇÃO DE PROTEÇÃO AO MEIO} AMBIENTE DE CIANORTE - APROMAC. Guia Básico: Gerenciamento de óleos lubrificantes usados ou contaminados, 2008. Disponível em: http://www. sindirepa-sp.org.br/pdfs/guia.pdf. Acesso em: 20 de Agosto de 2013. 
CONSELHO NACIONAL DO MEIO AMBIENTE - CONAMA. Resolução no 362, de 23 de junho de 2005. Disponível em: http://www.mma.gov.br/port/ conama/res/res05/res36205.xml. Acesso em: 20 de Agosto de 2013.

\section{CONSELHO NACIONAL DO MEIO AMBIENTE} - CONAMA. Resolução n ${ }^{\circ} 001$ de 23 de janeiro de 1986. Disponível em: http://www.mma.gov.br/port/ conama/res/res $86 /$ res 0186 .html. Acesso em: 20 de Agosto de 2013.

CONSELHO NACIONAL DO MEIO AMBIENTE - CONAMA. Resolução ${ }^{\circ} 275$, de 25 de abril de 2001. Disponível em: http://www.mma.gov.br/port/ conama/legiabre.cfm?codlegi=273. Acesso em: 20 de Agosto de 2013.

LOPES, G. V.; KEMERICH, P. D. da C. Resíduos de oficina mecânica: proposta de gerenciamento. Revista Ciências Naturais e Tecnológicas, Vol.8, n. 1, p. 81-94, 2007.

MARTINS, K. P.; MORAIS JÚNIOR, J. de A. Gestão de resíduos sólidos de oficinas mecânicas de João Pessoa/PB, 2010. Disponível em: http://www.redisa. uji.es/artSim 2010/Gestao/Gest $\% \mathrm{C} 3 \% \mathrm{~A} 30 \% 20$ de $\% 20$ res $\%$ C3\%ADduos $\% 20$ s $\%$ C3\%B3lidos $\% 20$ de $\% 20$ oficinas $\% 20$ mec $\%$ C3\%A2nicas $\% 20$ de $\% 20$ Jo\%C3\%A30\%20Pessoa.pdf. Acesso em: 01 de Setembro de 2013.

NUNES, G. B.; BARBOSA, A. F. F. Gestão dos resíduos sólidos provenientes dos derivados de petróleo em oficinas mecânicas da cidade de Natal/ RN, 2012. Disponível em: http://editorarealize.com. $\mathrm{br} /$ revistas/enect/trabalhos/Comunicacao_659.pdf. Acessado em: 07 de Junho de 2013.

PAULINO, P. F. Diagnóstico dos resíduos gerados nas oficinas mecânicas de veículos automotivos do município de São Carlos - SP. 74f. 2009. Trabalho de Conclusão de Curso (Graduação em Engenharia Ambiental) - Universidade Estadual Paulista, 2009.

SAVICZI, F. Técnicas de gestão de resíduos em empresas de reparação veicular, 2012. Disponível em: http://www.grcs.com.br/sindirepa/palestra 03. pdf. Acessado em: Acessado em: 27 de Agosto de 2013.

SINAL VERDE LIXEIRAS. Tambores com tampa vai e vem - 200 litros. Disponível em: http://www. sinalverdelixeiras.com.br/images/produtos/204_g. jpg. Acessado em: 27 de Agosto de 2013.

VALLE, C. E. do. Qualidade Ambiental: ISO 14000. São Paulo: SENAC, 2002.

Wikipédia: a enciclopédia livre. Localização Municipio Frederico Westphalen Rio Grande do Sul. Disponível em: http://pt.wikipedia.org/wiki/ Ficheiro:RioGrandedoSul_Municip_FredericoWestphalen.svg. Acesso em: 27-09-2013 